\title{
El teatro de la Universidad de Concepción durante la Unidad Popular (UP) en Chile 1970-1973. Democracia y política*
}

\author{
Luis Nitrihual Valdebenito** \\ Jenniffer Lobos Saavedra*** \\ Juan Manuel Fierro Bustos ${ }^{* * * *}$ \\ Javier Mayorga Rojel ${ }^{* * * * *}$ \\ Oscar Salinas Santelices ${ }^{* * * * *}$
}

Recibido: 2 de mayo de 2013 - Aprobado: 7 de junio de 2013

\begin{abstract}
Resumen
La presente investigación centró su preocupación en el teatro de la Universidad de Concepción durante el período de la Unidad Popular (1970-1973). Tuvo como objetivo analizar los imaginarios sociales de la democracia y del arte escénico, presentes en esta agrupación artística del sur de Chile. Mediante la aplicación de entrevistas en profundidad a actores clave, como instrumento de recogida de datos, y posteriormente, mediante un análisis cualitativo con el programa ATLAS/TI, se logró establecer que el imaginario social del arte y la democracia formó parte de un proyecto político donde el arte constituía parte de la regeneración propuesta por la izquierda de la época.
\end{abstract}

Palabras clave: arte, política, teatro, Chile, democracia.

Este artículo es fruto del Proyecto DIUFRO DI11-0006, financiado por la Dirección de Investigación de la Universidad de La Frontera.

* Doctor en Ciencias de la Información por la Universidad Complutense de Madrid. Periodista y magíster en Ciencias de la Comunicación por la Universidad de La Frontera (Temuco-Chile). Académico del Departamento de Lenguas, Literatura y Comunicación de la Facultad de Educación, Ciencias Sociales y Humanidades de la Universidad de La Frontera (Temuco- Chile) Director de la Carrera de Periodismo de la Universidad de La Frontera. Correo electrónico: luisnitrihual@gmail.com

... Periodista y Licenciada en Comunicación Social por la Universidad de La Frontera (Temuco-Chile), actualmente periodista del CNN Chile. Correo electrónico: jenlob@hotmail.com

.... Doctor en Ciencias Humanas por la Universidad Austral de Valdivia. Profesor de Estado en Castellano. Académico del Departamento de Lenguas, Literatura y Comunicación de la Facultad de Educación, Ciencias Sociales y Humanidades de la Universidad de La Frontera (Temuco- Chile) Vicerrector Académico de la Universidad de La Frontera. Correo electrónico: jmfierro@ufro.cl

....* Magíster en Ciencias de la Comunicación por la Universidad de La Frontera. Candidato a doctor en Ciencias de la Comunicación por la Universidad Autónoma de Barcelona. Académico del Departamento de Lenguas, Literatura y Comunicación, de la Facultad de Educación y Humanidades de la Universidad de La Frontera (Temuco- Chile). Correo electrónico: amayorga@ufro.cl

..... Profesor de Estado en Castellano. Magíster en Ciencias de la Comunicación por la Universidad de La Frontera (Temucho-Chile). Académico del Departamento de Lenguas, Literatura y Comunicación de la Facultad de Educación, Ciencias Sociales y Humanidades de la Universidad de La Frontera: osalinas@ufro.cl. 


\title{
Universidad de Concepción Theatre during the Popular Unit
}

\begin{abstract}
This research was specifically focused on the theatre of Universidad de Concepción during the Popular Unit period (1970 1973). The objective was to analyze social imaginaries of democracy and scenic art present in this artistic group of southern Chile. By applying deep interviews to key actors, as an instrument to collect data, and through a qualitative analysis with the ATLAS/ TI Show, it was possible to establish that social imaginary of art and democracy were part of a political project where art was part of the regeneration proposed by the left-wing politics of that period.
\end{abstract}

Key words: art; politics; theatre; Chile, democracy. 


\section{Introducción}

Investigar sobre las producciones artísticas es un trabajo fundamental para la investigación social. El arte constituye una parte importante de la formación social y de la identidad de una nación. En esta medida, pensamos que el arte es una producción social en la que la política no se encuentra ajena sino más bien imbricada. Su separación es solo un necesario ardid metodológico, pero luego es necesario volver a unir las piezas para elaborar marcos explicativos de mayor profundidad.

En este marco, nuestra investigación busca profundizar en el estudio del vínculo que mantuvo el arte escénico con las políticas de democratización y popularización, que constituyeron una parte relevante del proyecto popular chileno (1970-1973). Específicamente nos interesa conocer cómo las expresiones teatrales fueron un elemento relevante en la proliferación de un arte que buscaba ser popular, tal como lo consignaba el proyecto político allendista.

En el ámbito de la Educación Superior, las universidades de Chile, Universidad Católica de Chile y Universidad de Concepción se convirtieron en importantes centros de discusión política. Su compromiso social se hizo patente con las llamadas Reformas Universitarias ${ }^{1}$, que vivieron en el último tercio de la década del sesenta, tendentes a democratizar su estructura interna y reforzar su papel como agentes del cambio social.

La relevancia político-social de estas universidades también se expresó en sus manifestaciones teatrales. Así, el teatro de la Universidad de Concepción destacó como el más activo de los teatros de provincia, caracterizándose por la construcción de un teatro popular, descentralizado y con una identidad arraigada en su pertenencia al sur de Chile. Estudiar su propuesta teatral es, en este marco, adentrarse en la utopía que recorrió Chile entre 1970 y 1973 y que hacen de este periodo un excelente lugar para comprender el papel del arte en la construcción de un país.

\section{Metodología}

Metodológicamente, la investigación se desarrolló a partir de entrevistas en profundidad a actores clave, como espacio microsocial, y sus resultados nos permiten avizorar el espacio macrosocial de un período históricamente determinado.

1 Durante la segunda mitad de los años sesenta, las ocho universidades que componían el sistema universitario chileno experimentaron un profundo y extenso cambio. La reforma universitaria modificó de manera sustancial el contenido y las orientaciones de las funciones universitarias, estableció una nueva estructura de autoridad y poder que permitió la participación de la comunidad universitaria en el gobierno de las universidades y se esforzó por buscar una mejor inserción de éstas en los afanes por lograr el desarrollo y la modernización del país. Entre 1967 y 1968 todas las universidades se encontraban inmersas en el proceso de reforma universitaria. Las huelgas comenzaron primero en la Universidad Católica de Valparaíso y en la Universidad Católica de Santiago, luego en la Universidad Federico Santa María y en la Universidad Técnica (actual USACh), así como también en la Facultad de Filosofía y Educación de la Universidad de Chile y en la Universidad de Concepción. La reforma universitaria en Chile fue suspendida junto con la interrupción de la democracia el 11 de septiembre de 1973 (http://www.memoriachilena.cl/temas/index.asp?id_ut=larefor mauniversitariayelmovimientoestudiantil) 


\section{Arte escénico y sociedad: problema y objetivos de la investigación}

Durante el período de la Unidad Popular (1970-1973) en Chile, el gobierno de Salvador Allende realizó un importante esfuerzo por incorporar lo popular al espacio cultural, sirviendo así a los propósitos allendista de respaldar el proyecto político desde el pueblo ("desde el pueblo y para el pueblo").

Bowen (2008) señala que durante toda esta época se dieron en Chile múltiples escenarios de representaciones artísticas. El proyecto de revelación crítico sostenido por la izquierda chilena se aplicaba al ámbito del re-descubrimiento identitario y social del país a través de las expresiones artísticas:

Esto en la medida que tanto la identidad popular como la nacional habrían estado veladas por una capa culturalmente falsa, impuesta por agentes externos a su voluntad autónoma. Por ello, en cuanto al problema de lo nacional, la izquierda presentará su labor como de una independencia definitiva (Bowen, 2008).

En este mismo contexto, Bowen cita a Ossandón y Thumala para hacer ver cómo la sociedad chilena de ese entonces muestra, a través del arte, expresiones comunicacionales que representan ideales y pensamientos. De este modo,

El arte es verdad, justicia y libertad, anhelos permanentes del pueblo" (Ossandón, 1972: 76) y "las verdaderas obras de arte son valiosas para el hombre no como una sustitución de la realidad, sino como imagen artística que lo ayuda a reconocer y revelar la realidad (Thumala, 1972, p.11).

En este sentido, en la cultura política de la izquierda chilena varía radicalmente el modo de producción de la verdad que hasta entonces había operado, ya que para el arte y la cultura en transición al socialismo, la búsqueda de la verdad pasaba por una asimilación con lo que se consideraban los intereses de la clase proletaria. En este sentido, a la conciencia crítica le cabía siempre acceder a la verdad por sobre las mentiras de la burguesía (Bowen, 2008). Es aquí donde el teatro social desarrollado en el periodo de gobierno de la Unidad Popular (1970-1973) en Chile, particularmente el ofrecido por el TUC, en la ciudad de Concepción, tiene importancia como discurso social, sobre todo si se considera el importante fenómeno artístico que representó en el sur de Chile, y por qué no decirlo, en los ámbitos nacional y latinoamericano.

En un sentido general esto deja ver la relevancia del arte como fenómeno social. Más allá de la pura fruición, expresiones como el arte escénico permiten avizorar el entramado de los problemas sociales. Ya en trabajos anteriores (Galera y Nitrihual, 2009; Nitrihual y Galera, 2011) hemos planteado cómo el cine puede revelar esta complejidad en toda su magnitud.

Siguiendo estas preocupaciones, el objetivo de este artículo es reconocer el imaginario social del arte escénico y la democracia, presentes en el teatro desarrollado por la Universidad de Concepción (TUC), durante el período de la Unidad Popular (1970-1973). 


\section{Metodología}

Para hacer posible este trabajo se desarrolla una metodología cualitativa basada en entrevistas en profundidad aplicadas a informantes clave. El material recogido en las entrevistas fue posteriormente analizado con el software ATLAS/TI a partir de variables que dan cuenta de la percepción que tienen los sujetos (artistas de la compañía de teatro) sobre su papel y el del teatro durante este momento histórico de Chile.

\section{Cultura, política e imaginario social: los aportes teóricos}

\subsection{El gobierno de la UP: proyectos culturales y teatrales}

Desde antes que llegara Salvador Allende al poder (1970), existía una crítica a la sociedad capitalista -en mayor o menor medida- por el modelo de vida que se seguía en países como los Estados Unidos, potencia política que era vislumbrada como una nación imperialista. En un aspecto teórico interesante esto se representará desde los años sesenta con la llamada Teoría de la Dependencia, que viene a suministrar las claves de los procesos de subdesarrollo que viven los países del Tercer Mundo. Como señala Rodríguez:

En el contexto político nacional había una efervescencia ideológica con la llegada al poder del gobierno de la Unidad Popular. En este sentido, el cambio que se percibe en el teatro en estos años es el mismo que se corresponde con todos los movimientos artísticos, intelectuales y populares, esto es, con la sociedad en su conjunto, con una clara preocupación por lo social, desde una perspectiva "revolucionaria". El teatro se abocó a representar el registro del acontecer nacional (Rodríguez, 2001 - 200, pp. 51 - 58).

De este modo, y como reacción al imperialismo, apenas conseguido el poder, se pusieron en marcha las cuarenta medidas del Programa de Gobierno de la Unidad Popular (UP). Esta consistía en crear una "nueva" cultura para el país. Uno de los elementos clave de este programa es velar por la verdadera participación de los ciudadanos, que ya no serían solo consumidores sino agentes creativos y críticos de la realidad que se estaba viviendo. Esto, en el marco de la vía al socialismo.

El programa de Allende contaba con la seguridad "de que el arte es verdad, justicia y libertad, anhelos permanentes del pueblo"2 entendiendo esto como revelaciones a la verdad que se aprende al conocer y reconocer la vida diaria. De este modo se entiende que los artistas e intelectuales de la época - insertos en el nuevo modelo que trataba de implementarse- debían comprender su labor como una tarea que buscaba revelar la verdad $^{3}$.

2 Fragmento del Manifiesto del Taller de Teatro Libre de los Trabajadores del Acero, reproducido en Javier Ossandón, "El nuevo teatro aficionado", Revista EAC, N 1, Santiago, Escuela de las Artes de la Comunicación de la Universidad Católica de Chile, 1972, p. 76. Citado en Martín Bowen Silva, « El proyecto sociocultural de la izquierda chilena durante la Unidad Popular. Crítica, verdad e inmunología política », Nuevo Mundo Mundos Nuevos [En línea], Debates, 2008, Puesto en línea el 21 junio de 2008. URL: http://nuevomundo.revues.org/ index13732.html

3 Sobre este aspecto, a un nivel teórico, podemos sostener que el proyecto político de la Unidad Popular, obedece a la cuestión marxista clásica de la ideología: "ellos no saben lo que hacen, pero lo hacen". En este sentido, se trataba de revelar a esos que no saben "la verdad" (Zizek, 2001). 
En la primera convención de la Asociación Nacional de Teatro Aficionado de Chile (ANTACH), que se efectuó en diciembre de 1969, se propuso lo siguiente como marco de acción y proyección del teatro (Bravo, 1991):

1. Ser popular
a. Identificándose con los problemas e inquietudes del pueblo y con sus luchas de reivindicación social.
b. Manteniendo un nivel artístico digno.
c. Yendo hacia los sectores populares.

2. Ser formativo
a. Motivando la superación del nivel cultural y social.
b. Exaltando los valores humanos y sociales del pueblo.
c. Llevando a cabo una estrategia inteligente a través del montaje de obras de entretenimiento o de fácil comprensión para un público no acostumbrado al fenómeno teatral y deformado por órganos de publicidad.
d. Montando obras que tanto en sus obras como en su forma presenten caracte- rísticas de creatividad y que motiven una toma de conciencia para un público ya preparado" (Fernández, pp. 180-181 citado por Bravo, 1991, pp. 146).

Como puede notarse, se trata de concebir al teatro como una expresión de redescubrimiento de la identidad popular nacional. Esto es consecuente como la idea de la cultura como un espacio de independencia nacional. Por esta razón, la política cultural de la UP relevaba de manera importante los sentimientos de pertenencia, debido a que se devolvía "el habla" al pueblo; como señala Bowen (2008):

\begin{abstract}
Tarea que se lograría a partir de la participación activa de los trabajadores en la creación, discusión y difusión de los mensajes sociales. Esta participación crítica, acompañada de una efectiva praxis revolucionaria (que funcionase como correlato estructural a este cambio en la superestructura), permitiría al pueblo superar su disminuida situación cultural.
\end{abstract}

\title{
3. Los imaginarios sociales: ideología y democracia
}

El concepto de imaginario social proviene del trabajo del filósofo griego Cornelius Castoriadis (2007). Es, sin duda, uno de los aportes teóricos más relevantes que legó el autor a las ciencias sociales. El concepto de imaginario hace referencia a lo inventado, ya sea como ficción absoluta o como superposición de lo simbólico por sobre lo real. En un sentido profundo, siempre nos encontramos articulados sobre lo simbólico que, desde luego, no es lo real. En este sentido, entendemos el imaginario o la memoria no solo como un cúmulo de saberes adquiridos (como el lenguaje y ciertas interacciones) sino aquellas ideas que poseen la cualidad de expresar y dar forma a los intereses, los temores, los deseos, los rechazos y las esperanzas de las personas que forman una colectividad, la cual se define precisamente por esos referentes comunes. Es interesante reflexionar que la construcción de lo imaginario parte desde lo individual. Manuel Antonio Baeza define de manera simple 
los imaginarios sociales como "múltiples y variadas construcciones mentales socialmente compartidas de significancia práctica, en sentido amplio, destinadas al otorgamiento de sentido existencial" (Baeza, 2003, p. 20).

Profundamente, los imaginarios sociales son una red de significaciones que atraviesan a los sujetos sociales:

Esta red de significados es lo que yo llamo el magma de las significaciones imaginarios sociales, las cuales son llevadas por la sociedad e incorporadas a ella y, por así decirlo, la animan. Tales significaciones imaginario sociales son, por ejemplo: los espíritus, los dioses, Dios; la polis, el ciudadano, la nación, el Estado, el partido, la comodidad, el dinero, el capital, la tasa de interés; el tabú, la virtud, el pecado, etc. Pero también son el hombre/la mujer/el niño tal como se especifican en una sociedad; más allá de las definiciones puramente anatómicas o biológicas, el hombre, la mujer y el niño son lo que son en virtud de las significaciones imaginario sociales que los hacen ser precisamente eso que son (Castoriadis, 2003, p. 5).

Todo esto se contempla desde la experiencia social y son las creencias, prejuicios y juicios, memoria, intelecto y distintos esquemas que cada uno construye, pero que tienen un origen colectivo. Desde aquí se puede entender que hablar de sociedad es hablar de identidad social, algo socioimaginario, según Baeza, que se reviste de un estatuto simbólico y moral y permite la cohesión de la sociedad.

La representación (mental) que el grupo se hace de sí mismo no puede perpetuarse sino en/y por el trabajo incesante de representación (teatral) mediante el cual los agentes producen y reproducen, aunque fuere en y por ficción, la apariencia al menos de la conformidad a la verdad ideal del grupo, a su ideal de verdad (Baeza citando a Baudiere, 2003, pp. 20).

De acuerdo con ello, nadie estaría violando el "protocolo elemental de la vida en sociedad"; solo se debe hablar de imaginarios dominantes ("naturales") e imaginarios dominados. "Un imaginario social llega a ser dominante cuando lo presentado como "natural" logra vestirse con los ropajes de lo "no ideológico" (Baeza, 2003, pp. 28). Muy similar a este carácter de lo imaginario, coincidimos con Zizek (2003) cuando señala que el nivel profundo de la ideología se manifiesta justamente cuando no se hace evidente y pasa por natural (estamos sentados sobre la ideología).

Una ideología se "apodera de nosotros" realmente solo cuando no sentimos ninguna oposición entre ella y la realidad - a saber cuando la ideología consigue determinar el modo, nuestra experiencia cotidiana de la realidad (Zizek, 2001, p. 81).

Ahora bien, los imaginarios sociales -como señala Juan Luis Pintos- posibilitan:

Unas referencias semejantes de percepción (espaciales, temporales, geográficas, históricas, culturales, religiosas, etc.), de explicación (marcos lógicos, emocionales, sentimentales, biográficos, etc.) y de intervención (estrategias, programas, políticas, tácticas, aprendizajes, etc.), todo ello referido al elemento siguiente. Además se debe explicitar que lo que en cada sistema social diferenciado se tenga por realidad: no hay una única realidad, que se identificaría necesariamente con una verdad única. Nuestras sociedades contemporáneas no se configuran bajo el modelo de sistemas 
únicos y de referencias absolutas, sino que están sometidas a procesos evolutivos de progresivas diferenciaciones sistémicas. Aparecen así históricamente modos de comunicación diferenciada por códigos y programas por los que el sistema se vuelve funcional a las exigencias del entorno produciendo ámbitos específicos de operación (política, ciencia, derecho, economía, religión, etc.). En cada uno de esos subsistemas se tratan de definir como realidades únicas las que se corresponden a los intereses contrapuestos de las organizaciones que operan en su interior (Pintos. 2005, pp. $35-65)$.

En este mismo sentido, es interesante indagar en profundidad en los imaginarios que se vivían durante el período de la Unidad Popular en Chile. Puntualmente, imaginarios como los de la democracia son interesantes de indagar por la relevancia que este concepto tiene en la articulación de los sistemas sociales modernos. Juan Luis Pintos (2005) describe muy bien cómo se generan oposiciones en el campo de social.

De este modo se opera propiamente en el campo de construcción de realidad respondiendo a intereses generales, de las organizaciones particulares o de los individuos. La forma de la comunicación, en cada medio concreto es la de señalar las relevancias dejando fuera de la percepción comunicativa las opacidades que podrían dañar los intereses que representa. Los discursos suelen así deslizarse hacia la trivialización y expresar expectativas (tópicas o utópicas) que casi siempre desembocan en un estuario de confusión entre la "buena conciencia", la moral pública y nuevos procesos de inclusión/exclusión (Pintos, 2005, pp. 37-65).

Cristina Peñamarín (2002) explica que entender la significación que tiene lo simbólico implica acercarse a lo afectivo, a las relaciones que establecemos con el mundo y con los otros. Desde esta base podemos entender que durante el período de gobierno de la Unidad Popular el anhelo mayor fue la búsqueda de un "territorio simbólico" que resemantizara la identidad nacional. Consecuente con esto, era necesario representar y difundir ciertas formas de hacer teatro y representar "lo chileno".

\section{Propuesta metodológica}

La investigación tiene un carácter descriptivo (Hernández, Fernández y Baptista, 2006, p. 80). El instrumento de recogida de datos es la entrevista en profundidad, entendida como una:

Técnica mediante la cual el entrevistador sugiere al entrevistado unos temas sobre lo que este es estimulado para exprese todos sus sentimientos y pensamientos de una forma libre, conversacional y poco formal, sin tener en cuenta lo "correcto" del material elegido (Pérez, 1998, p. 41).

Por medio de las entrevistas en profundidad, se buscará determinar cómo realizaba los montajes el grupo de teatro TUC, con el fin de entender cuál era el enfoque que ellos daban a sus obras, ya sea a través del tratamiento de determinadas temáticas, roles y funciones de actores e integrantes de la compañía, ya sea desde los discursos comunicacionales y el tipo de composición estética de las puestas en escena abordadas durante esa época. Buscamos identificar y reconocer el imaginario social del arte escénico y la democracia presentes en el teatro de esta agrupación durante los años 1970 a 1973. 
Los criterios de selección de los entrevistados son los siguientes:

- Haber participado en el TUC y vivenciado a través del quehacer teatral desarrollado, parte de la experiencia e identidad del TUC en el sur de Chile.

- Accesibilidad, ya sea por su presencia en la zona, salud y disposición personal para con la entrevista.

De esta manera se logró ubicar a cinco informantes clave a los cuales se les aplicó un protocolo de la técnica de entrevista, basada en tópicos y subtópicos de las materias que nos interesó indagar.

Una vez hecho el registro y recopilados los antecedentes por medio de entrevistas, se procedió a un análisis cualitativo a través del software de análisis de datos ATLAS/TI. Esta herramienta informática es de análisis cualitativo de datos textuales, cuyo objetivo es facilitar el análisis. El proceso de su análisis es un ir y venir entre la fase textual y la conceptual que se desarrollan de manera secuencial, principalmente a través citas y códigos. Ello permitió establecer veintitrés categorías que luego fueron pesquisadas.

1. Arte.

2. Compañerismo.

3. Democracia.

4. Discurso comunicacional.

5. Estrategia comunicacional.

6. Gobierno UP.

7. Identidad.

8. Ideologías políticas.

9. Masa crítica.

10. Profesionalismo.

11. Programa cultural gobierno UP.

12. Pueblo.

13. Realidad.

14. Realismo.

15. Reflexión.

16. Revolución.

17. Salvador Allende.

18. Teatro.

19. Teatro social.

20. Teatro político.

21. Teatro universitario.

22. Tendencia de izquierda.

23. Utopía. 


\section{Resultados de la investigación}

El análisis realizado con base en las categorías planteadas generó mapas conceptuales según categorías y subcategorías que luego se dividieron en distintas familias: política, cultura, sociedad y formación técnica del objeto de estudio (TUC). El primer mapa muestra las relaciones de todas las categorías de análisis:

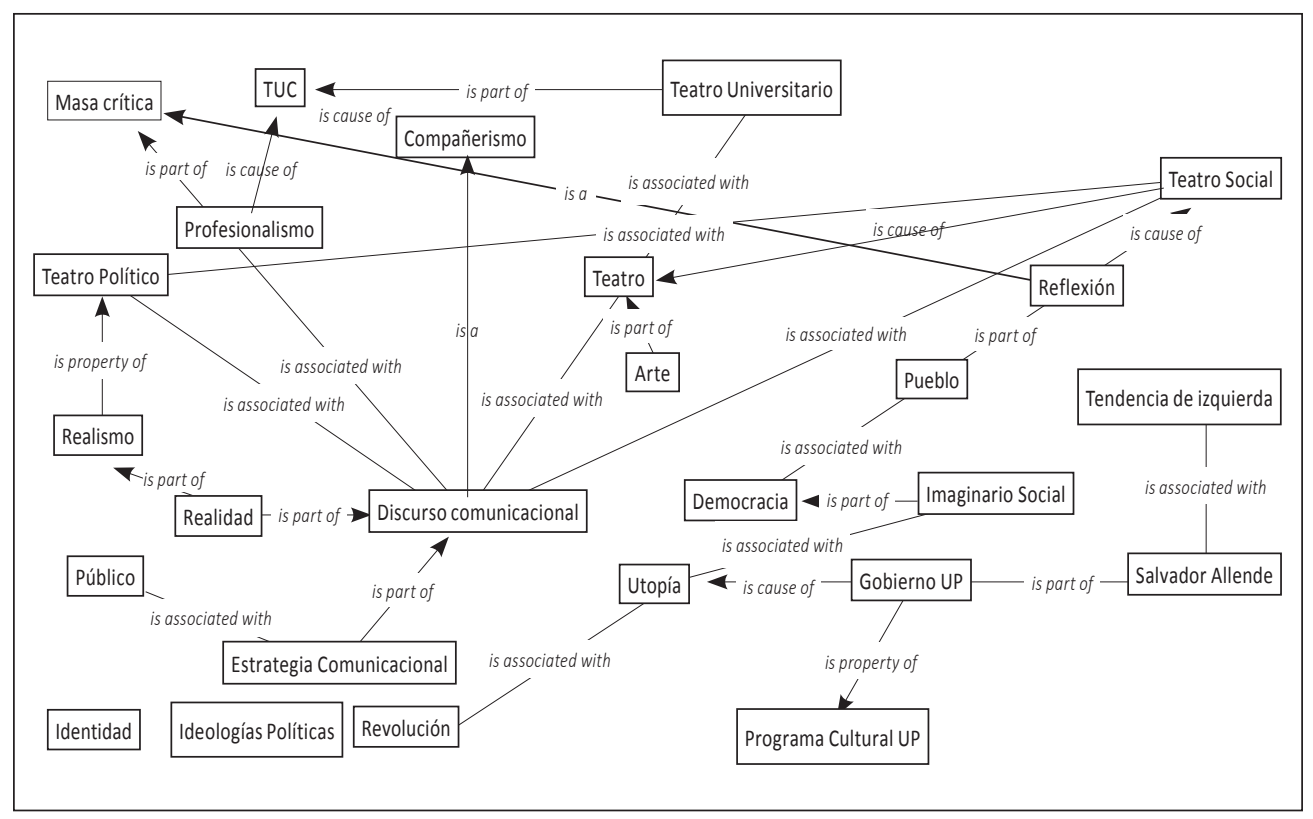

Mapa 1.

Fuente: elaboración propia.

Este esquema representa todas las categorías junto a sus subcategorías. La línea más gruesa señala que la reflexión se vincula con la masa crítica de la época que constituye parte del profesionalismo y objetivo del trabajo del TUC. El arte y el compañerismo se sustentan en estrategias que permiten entregar un discurso comunicacional acerca de la realidad contingente, representado a partir del realismo, y que genera un teatro político que involucra un teatro social basado en categorías como la reflexión, el pueblo y la democracia, que son parte de una propuesta política de la izquierda.

El mapa n. ${ }^{\circ} 2$ muestra la categoría política. Este mapa de relaciones, que se establece a partir del discurso de los entrevistados, refleja cómo la política se relaciona con el gobierno de la Unidad Popular y su proyecto cultural. La búsqueda de un horizonte utópico basado en la propuesta socialista, liderada por Salvador Allende, permite vislumbrar cómo arte y política se encontraban íntimamente relacionados. 


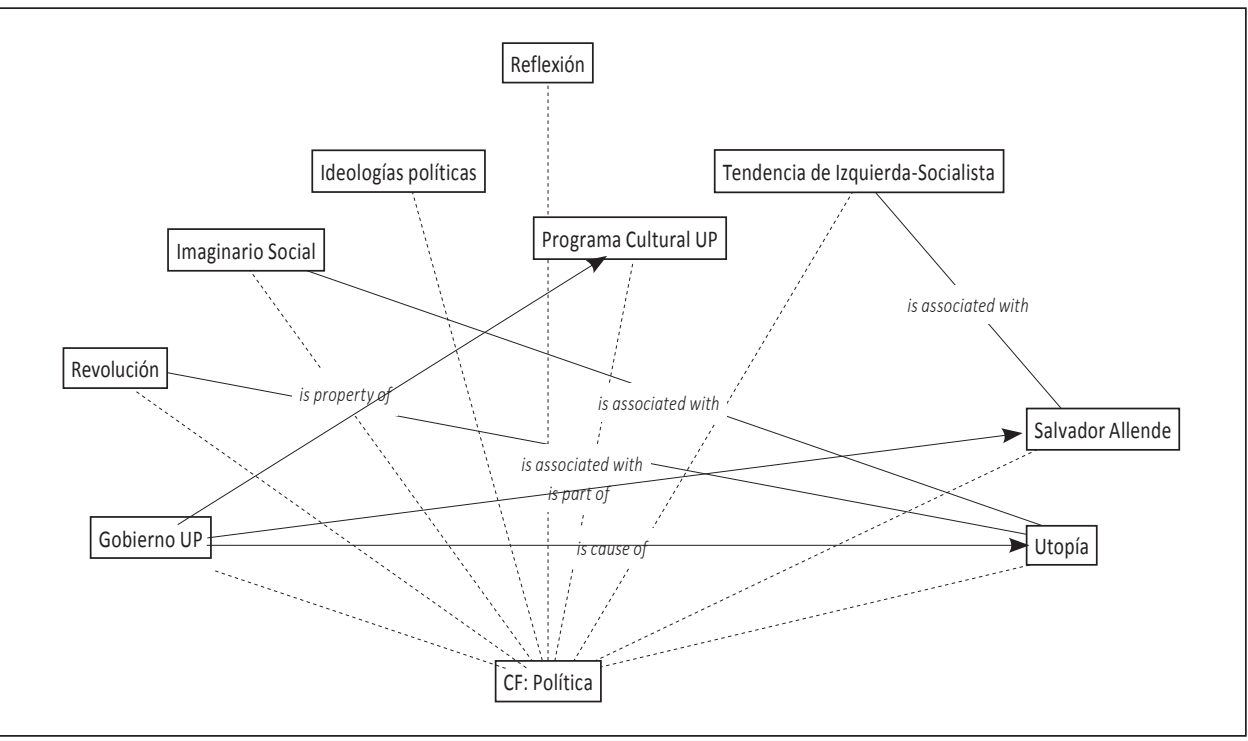

Mapa 2.

Fuente: elaboración propia.

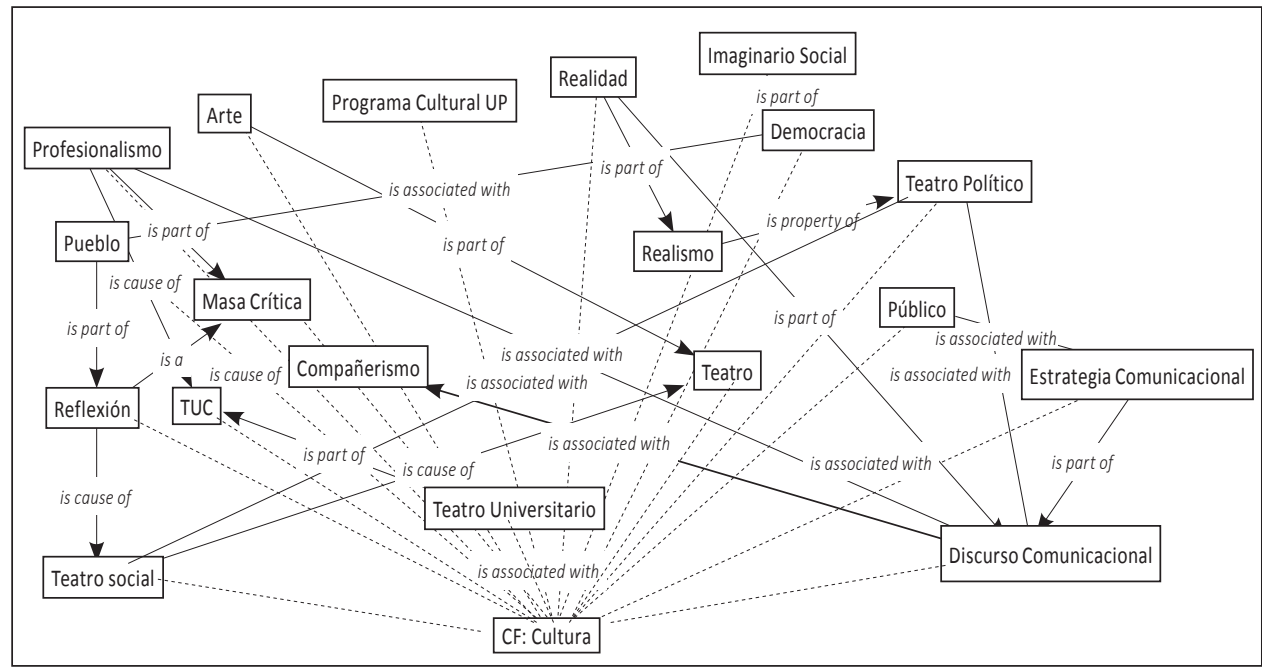

Mapa 3.

Fuente: elaboración propia.

El mapa n. 3 aborda el concepto de cultura, engloba los aspectos del discurso comunicacional, el TUC y el imaginario social que vive el arte en la época de 1970 y 1973 , donde la realidad que existe forma parte de un teatro político asociado a un teatro social basado en la reflexión y el profesionalismo con que el TUC enfrenta su trabajo. 


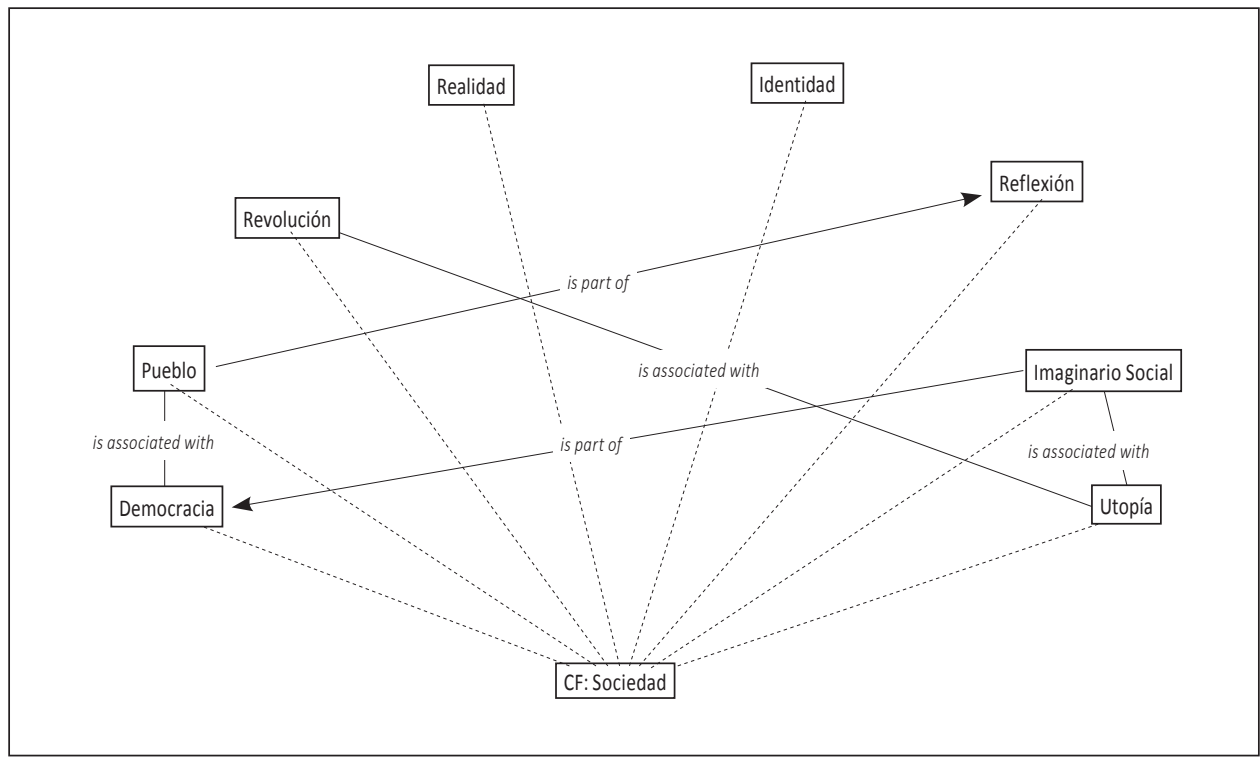

\section{Mapa 4.}

Fuente: elaboración propia.

En el mapa no 4 se refleja la sociedad de la época, donde existe un imaginario social de la democracia que está asociado directamente con la noción de pueblo y que busca la reflexión acerca de la realidad contingente incorporando una utopía en la revolución que desea implementar en el gobierno de Salvador Allende. Esta sociedad, por medio del arte, indaga y construye su propia identidad.

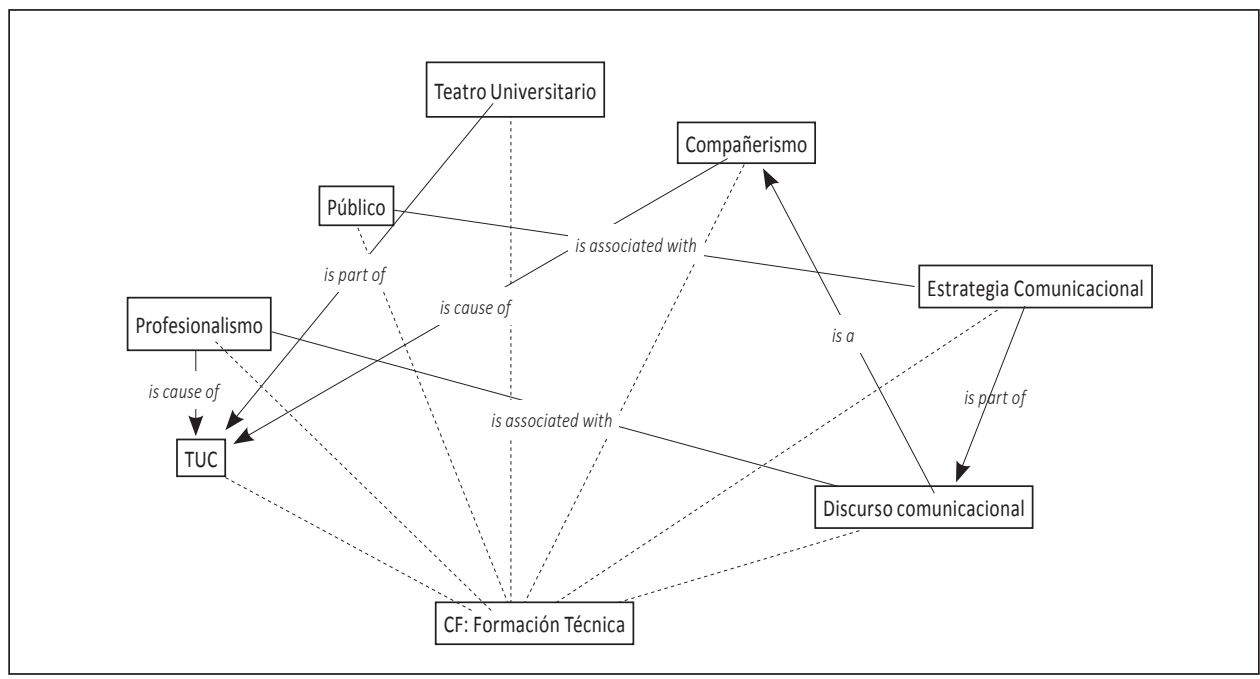

Mapa 5.

Fuente: elaboración propia. 
El mapa n. 5 representa el esquema de la formación técnica y, por ende, académica del TUC. Esta categoría muestra como el profesionalismo y el compañerismo son la base del quehacer artístico de la compañía.

Ahora bien, respecto a los supuestos de la investigación que señalaban que durante la época de la Unidad Popular existió una tendencia en las expresiones del Teatro de la Universidad de Concepción (TUC), de representar discursos políticos e imaginarios sociales de democracia socialista, determinados por el contexto sociocultural en el que se encontraba el país y que se expresaba provincialmente en el teatro que producía esta agrupación escénica, se reveló lo siguiente:

a) A la luz de la propuesta de análisis presentado, se reiteran las nociones de pueblo, reflexión, teatro social, democracia y tendencia de izquierda, como conceptos que forman parte de idearios del bien común y la justicia social y que sustentan el quehacer artístico de los entrevistados.

b) Asimismo, los idearios de arte y cultura, también manifestados en las citas de las entrevistas, se encuentran asociados a una concepción particular de la democracia. Asimismo, los mapas conceptuales resultantes de política, cultura, sociedad y formación técnica teatral, se encuentran entrelazados y permiten determinar que los integrantes de TUC se sienten parte del bien común asociado al proyecto de la Unidad Popular o a la tendencia socialista de la época. Con base en estos antecedentes podemos aseverar que existió durante la época de la Unidad Popular una tendencia en la expresión comunicacional del Teatro de la Universidad de Concepción para representar imaginarios sociales de la democracia socialista, imaginarios determinados por el contexto sociocultural en el que se encontraba el país y que se expresaba provincialmente en el teatro social que producía esta agrupación escénica.

Una cuestión interesante en el análisis y que se encontraba por fuera de los supuestos iniciales es que la práctica teatral de esta agrupación es concebida como profesional (entendido como opción por el arte y la aplicación de la técnica escénico-teatral), práctica que se manifiesta en forma categórica y recurrente en las respuestas de los entrevistados. Se reitera la afirmación de que el objeto teatral no está influenciado por las opciones políticas particulares de sus integrantes, afirmando permanentemente que lo que existe es un vínculo del teatro y de todas las artes con el desarrollo de la sociedad, categoría que no puede relacionarse con opciones ideológicas particulares.

De acuerdo a esto, predominó el profesionalismo de la compañía. El teatro que se desarrolló, en esta medida, es principalmente un teatro social.

\section{Conclusiones de la investigación}

Considerando el objetivo de esta investigación, podemos sostener lo siguiente:

1) A través de esta investigación se logra reconocer que el desempeño de los artistas y directores del TUC durante el periodo analizado manifestó una búsqueda de la democracia, así como de representar obras a la luz de una concepción de teatro 
social, donde los conceptos de reflexión y justicia social se encuentran asociados a sus roles teatrales.

2) El TUC, por sus formas expresivas, a la luz de la información/experiencia que podemos reconocer a través de las entrevistas y citas, nace efectivamente como un espacio de difusión de ideas populares que se formula desde este teatro social, muchas veces expuesto tanto en poblaciones (lugares populares) como en lugares de la élite cultural.

3) Durante los años setenta, el TUC abordó temáticas sociales a través de sus puestas en escena para constituirse en reflejo de los acontecimientos de la época; allí las composiciones estéticas no dan cuenta de expresiones políticas determinadas, sino de una opción temática por el teatro social. Es así como señalan, a través de las entrevistas, que para realizar esta labor se trabajó un teatro con contenido social y bien hecho, y compartieron la reflexión grupal y del público. En esto se muestra una profunda concepción del arte como parte del desarrollo social del país. Recordemos que uno de los ejes en los que se centraba el programa allendista era educación y arte popular.

4) Se desglosa, asimismo, según los gráficos y estadísticas de la investigación, que el TUC durante la Unidad Popular, surge como un espacio de difusión de ideas populares, ya que reconocen su rol activo en lo que estaba pasando en la sociedad.

Mientras que las temáticas teatrales que se trabajaban entre 1970 y 1973 cumplían con un rol social, es interesante mencionar que a través de las entrevistas realizadas se desprende que se había iniciado una politización de la sociedad que lentamente afectaba las condiciones del trabajo teatral. Como señalan los entrevistados, con las posturas políticas extremas se hacía difícil decir lo que se pensaba, actuar con ideales, buscar los principios del TUC: democracia, justicia y conciencia social para construir y aportar con lo que mejor sabían hacer, su trabajo, el arte escénico profesional.

El teatro se concebía entonces como una de las artes que debía salir de los claustros para conquistar a nuevos públicos, para dar la oportunidad a la gran masa de asistir a los eventos culturales. El concepto de reflexión, de llegar al pueblo por medio de un teatro social, claramente tiene una tendencia de izquierda. Por ello, la reflexión del teatro social que realizaron era fundamental. Se buscó luchar por quienes no podían hacerlo: lo pobres. Había que demostrar que su trabajo iba directamente dirigido al pueblo, a buscar justicia social. Las estrategias comunicacionales del TUC consistían, en este marco, en establecer nexos con distintas agrupaciones sindicales para mantener una relación con el entorno.

Por último cabe señalar que los años sesenta estuvieron llenos de utopías y sueños, y el teatro era una manera de entregar un pensamiento que tenía ideales y que reflejaba lo vivido por la sociedad. 


\section{Referencias bibliográficas}

Baeza, Manuel (2003). Imaginarios Sociales: Apuntes para la discusión teórica y la metodología. Chile: Universidad de Concepción.

Bowen, Martín (2008). El proyecto sociocultural de la izquierda chilena durante la Unidad Popular. Crítica, verdad e inmunología política, Revista Nuevo Mundo Mundos Nuevos [En línea], Debates, 2008, Puesto en línea el 21 enero 2008, Consultado el 13 abril 2012. URL: http://nuevomundo.revues.org/13732.

Bravo, P. (1991). Raíces del teatro popular en Chile. Guatemala: Impresiones DEM.

Castoriadis (2003). El campo de lo social. Estudios, Filosofía-Historia-Letras. [En línea]. Puesto en línea en 2003. URL: http://www.hemerodigital.unam.mx/ANUIES/itam/estudio/estudio04/sec_3.html

Hernández, R.; Fernández, C. y Baptista, P. (2006). Metodología de la Investigación. México, D. F., Mc Graw Hill.

Nitrihual, L. y Galera, J. (2011). "Romeo y Julieta de Cantinflas. El humor en la cultura de masas" Arte Individuo y Sociedad Vol. 2, n. ${ }^{\circ} 23$.pp. 97-107.

Galera, J. y Nitrihual, L. (2009). "Cantinflas entres risas y sombras. Un análisis semiótico cínico" Revista Anagramas n. ${ }^{\circ}$ 15. pp. 99-115.

Pérez, Gloria (1998). Metodología de la investigación cualitativa, retos e interrogantes. Madrid: Editorial La Muralla.

Pintos, Juan Luis. 2005. Comunicación, construcción de la realidad e imaginarios sociales, Revista Utopía y Praxis Latinoamericana. Año 10. N. ${ }^{\circ} 29$. pp. 37-65.

Rodríguez, Claudia. (2001-2002). Notas para una historia del teatro en Chile (II). Revista Documentos Lingüisticos y Literarios UACh 24-25: 51-58

URL: http://humanidades.uach.cl/documentos_linguisticos/document.php?id=145.

Zizek, Slavoj (2001). El sublime objeto de la ideología. Buenos Aires: Siglo XXI. 
